that this had existed for some time, about four or five months after that event, but then gradually got better; that, unlike her other occasions, she had no "show", nor any vestige of discharge whatever. I informed her of what was necessary to be done, and she at once assented.

I had no instrument with me but a lancet, and time did not allow of going or sending home for anything better, as the vertex, pressing powerfully on the highly stretched wall of the uterus, now reached the labia pudendi at every pain. I wound a narrow strip of rag round the handle and joint of the lancet, to render it fixed; and, taking into my service the nurse, who, fortunately, was a young intelligent married woman, $I$ in structed her (placed at the patient's back) to insert the fore and second fingers of her right hand behind the fourchette or posterior angle of the vulva, and keep back the parts during next pain, so that I might see the actual state of the os, or of the adventitious substance by which it was hidden. This done, there was presented to view a quite smooth and continuous surface, the only distinctive indication discoverable being a slightly more livid hue of the new vascular formation which occupied the space of the natural aperture. I hastily pointed out this to the nurse, who, as well as she was able, marked the distinction. On recurrence of a pain, I made three or four scarifications with the lancet, all in the same line from right to left of the patient, producing an elliptical gap or separation in the new substance. I thus obtained partial admission of the point of my finger, with which $I$ by degrees widened the opening to the extent of a shilling piece, distinctly perceiving that, in so doing, I had to break down what was more substantial than membrane-in fact, to the best of my judgment, was homogeneous with the parenchyma of the organ itself. I then ruptured the proper membranes: there was a considerable discharge of the waters, and everything went regularly on as in an ordinary case, but so rapidly that, within ten minutes from my using the lancet, a full-sized healthy female child was born; and no unfavourable circumstance has happened to mother or child to this time.

Such a case occurring to the young student, as yet innocent of the peculiarities occasionally to be met with in this branch of his profession, might prove (judging from my own recollections) bewildering in the extreme. But, in the hands of an ignorant midwife, or of one of those infamous impostors whose malpractice and its frequently horrible results our legal functionaries delight to shield from punishment, the reports of torture and mutilation, and of life sacrificed to gross presumption or bold reckless ignorance, indicate as too probable a more lamentable issue. In the outset, I have alluded to its singularity in my own experience, and have qualified my admission of anything similar in that of others. With your permission, I will, on a future occasion, state the grounds of that qualification.

\section{SOME PRACTICAL OBSERVATIONS ON THE BEST METHODS OF INTRODUCING THE CATHETER IN CASES OF EXTREMELY NARROW AND IRRITABLE STRICTURE.}

By Henry Thompson, Esq., F.R.C.S., M.B.Lond., Assistant Surgeon to University College Hospital; Consulting Surgeon to the St. Marylebone Infirmary.

[Read before the British Medical Association, July 30th, 1857.]

THE object of the paper which I have the honour of presenting to the Association, is to offer as briefly as possible a few practical remarks on the best methods of passing a catheter through narrow and obstinate, or irritable organic stricture of the urethra, and of introducing it into the bladder, whether in the crisis of retention or otherwise.

I venture to recommend to the consideration of my brethren a course of practice which I have myself found successful in several cases of considerable difficulty, with the assurance that in the very large majority of cases it will enable us fairly and completely to afford relief by the catheter alone, without having recourse to the knife, and especially to that uncertain and sometimes hazardous method of dissecting through the deep tissues of the perineum, from the point of a catheter introduced as far as to the face of a stricture, but not through itin other words, the operation long known as that of "the perineal section". And I conceive that, without entering upon any discussion of the relative merits of the knife or of the trochar, there can be but one opinion, that relief by the catheter, where it can be afforded without force or damage, is the most desirable result for the patient. At the same time, it may be stated, once for all, that the faintest approach to anything like forcible catheterism in stricture of the urethra is deprecated here, not only as a dangerous, but also as generally an unsuccessful expedient.

It is now many years since Mr. Syme, of Edinburgh, expressed in forcible terms, his belief that in every case of stricture, if the urine passed outwardly, a catheter could with care and perseverance be passed through it into the bladder. Five years ago, I stated in my work on stricture, presented to the Royal College of Surgeons for the Jacksonian Prize, that my experience at that time compelled adhesion to the opinion that cases of failure with the catheter ought to be exceedingly rare. And I may say now, that a much larger experience has but confirmed that belief. During the period named, I have met with but one among the numerous and obstinate cases which I have been called upon to treat in private and in public, in which I have not, sooner or later, succeded by the gentle use of the catheter in reaching the bladder. The case referred to was sent me by a gentleman in the Isle of Wight, and was an example of the disease in its most advanced stage and aggravated form, occurring in a thoroughly broken constitution. I ultimately relieved him by puncture of the bladder; and at death, about two months subsequently, with dis organisation of the kidneys, no catheter, however small, could be carried through a long and indurated stricture, although the urethra had been laid open as far as to the point of obstruc. tion; nevertheless, the canal was not absolutely obliterated, for drop or two of urine would occasionally pass through.

I beg leave, with the utmost deference, in the presence of so many of my distinguished confrères, to advert very briefly to the two or three simple means which have appeared to me greatly to facilitate the introduction of the catheter, in those cases in which the existence of more than usual difficulty has been verified. I would, however, first advert, and but for a moment, to the use of those constitutional means which, by the consent of all surgeons, are to be regarded as of great value in the circumstances described. And in order to do so in as few words as possible, we will suppose the case of a patient, with a twenty years' history of stricture, with fistulæ in the perineum, through which a large portion of the urine passes, with micturition painful and exceedingly frequent both by night and day, little urine passing by the external meatus, and that either in a slender stream or by drops. Further, that ordinary means, while visiting his surgeon on several occasions, have not enabled the latter to pass any instrument through the stricture, and that it has therefore become obvious that some other measures must be adopted in order to afford relief. There can be no doubt that in such circumstances much local irritation exists about the seat of stricture, and that there is much congestion of the already narrowed portion of the canal. The obstruction thus produced is often very materially diminished by a few days of rest in bed, by laxative medicines, a free supply of mild drinks to dilute the urine and destroy its acidity, hot hip-baths, a warm temperature to promote the action of the skin, and opiates, especially per rectum, if necessary.

After noting the improvement which usually follows such treatment in the case of a patient whose ordinary habits of life aggravate his complaint; after a week's lapse of rest to the urethrs since any preceding attempt; the mode of conducting the first trial of the catheter constitutes one of the points which to me appears worthy of attention. In such circumstances, I prefer of all seasons to visit the patient early in the morning while he is in bed, when the skin is warm and moist after sleep under ample coverings.

When introducing an instrument, it is necessary that there should be no chill : all unnecessary exposure should be therefore carefully guarded against. Premising that the precise situation of the stricture has been carefully verified beforehand by passing a full-sized graduated instrument to the obstruction, and noting its distance in inches from the external meatus (or if not that, it is done at once), a small silver catheter may be selected. The size of this is, I think, to be determined by the known size of the stream of uine habitually passed; and this is best learned by ocular observation on one or two occasions, as patients often fail to represent it very accurately by words. As a rule, without entering upon the grounds on which this conclusion is based, the magnitude of the catheter selected should be a little less than that of the stream of urine. In the next place, it will be obvious in oiling the instrument, that the smaller it is, the less will be the quantity of oil which can be made to adhere to it; while it is 
no less true, that just in the same proportion as the instrument diminishes in size, so does the presence of oil become increasingly necessary. All will agree that the smaller the instrument, the greater is the danger of injuring the urethra that it is, in short, an axiom of the highest importance, that an instrument should never be employed a single degree lower in the scale than is absolutely necessary. But, granted that we require a small instrument for the case in point, it is a matter of no little importance to ascertain how we can best protect the urethra from injury or pain incident to the proceeding; and at the same time, facilitate the passing of the instrument through the stricture.

These objects may, in a great measure, I think, be attained by the simple method of applying the oil to the uretlvra itself, and very freely, rather than to the instrument. In order to affect this, the nozzle of a common glass syringe, containing from four to six drachms of pure olive oil, should be introduced into the urethra as far as it will go, the external meatus being at the same time elosed upon the nozzle by the forefinger and thumb of the left hand, so that none can escape. Gentle pressure being now made on the piston-rod, the oil gradually finds its way down to the stricture; and if this be very narrow, the urethra in front of it slowly fills and becomes slightly distended; but as the piston continues to descend, the oil will gradually pass through the stricture, and onwards into the bladder, thoroughly lubricating every part of the canal. At the moment the oil passes through the stricture, the operator may sometimes distinctly perceive a slight but very complete sensation communicated to the hand, of resistance overcome, and partial collapse of the previously distended urethra in front. The syringe is then to be removed, the finger and thumb still commanding the meatus of the urethra, so that no oil escapes. The smallest catheter may now be introduced, and made to traverse the urethra - at all events, as far as to the stricture-with very little or none of that difficulty arising from the catching of its point against the walls of the passage, so often experienced with very small instruments, and which renders so much care necessary in their employment. But what is more, when arrived at the stricture, the instrument, if adapted in size, will gradually pass through it; or, at least, the probability of its doing so is greatly increased. The narrowed channel has not only been thoroughly lubricated but somewhat distended by the mechanical pressure of the column of oil which has passed through it; and this sometimes occurs to an extent which affords no inconsiderable amount of aid to the operator. On the other hand, in adopting the ordinary method of oiling or greasing a small catheter, no one can doubt that all the lubricating material has been removed long before it reaches the usual situation of stricture, the very part at which, if required at all, its presence is especially needed.

I am satisfied, from my own personal experience, that I have obtained a considerable advantage from the use of oil in this manner. No weight would be added to this assertion by the recital of cases, by which the length of this communication might easily be doubled, because the particular influence of any single given agent under such circumstances-that is, one acting simultaneously with several others - must be purely a matter of opinion. The success which has followed its use in my hands has nevertheless been witnessed by several, who have themselves adopted it in consequence. Furthermore, patients suffering with very irritable stricture have experienced so much less pain from the passage of a catheter after the injection of oil, that I have been repeatedly requested by them to employ it on subsequent occasions.

To return for a moment to the question of size as regards the catheter to be employed. Repeating a rule which cannot be too strictly adhered to, that danger increases conversely with the size of the instrument employed, we yet may not overlook the fact that experience shews that some of the worst and most obstinate forms of the disease have been proved after death to consist of a narrowing of the channel so extreme, that no instrument which is sufficiently small to pass through it can be made hollow so as to act as a catheter. When such a case presents, I have been able to succeed by the employment of smaller instruments than those usually employed-at all events, in solid material. But it appears to me to be especially desirable in such eases to use, if possible, a hollow instrument; one that has the power of conveying the urine outwards, and so of assuring the operator that he has fairly and successfully freed the stricture, and has arrived at the bladder. Indeed, the smaller the instrument, the more desirable is it that this practical test of its safe position should be afforded. I have long felt how desirable-indeed, how almost necessary -it is to combine in one instrument the quality of tubular construction with minute size; the possibility of making it sufficiently small to be capable of entering the narrowest stricture; and, at the same time, so strong and steady in the hand, as not to bend like flexible bougies, and thus deceive the operator.

This desideratum, as it appears to me, is supplied by the instrument to which I beg leave to request your attention, and which has recently been described as "the probe-pointed catheter". I designed it in the first instance, now nearly two years ago, for a case of great difficulty, in which the stricture was considered impermeable; and, practically speaking, had been so to all instrumental attempts for many years. Nevertheless, a few drops passed by the meatus, and I was convinced that if I possessed an instrument sufficiently small with sufficient solidity to enable me to guide it, it ought not to be impossible to insinuate it through the stricture. But I felt how doubly necessary it would be with such an one to obtain a guarantee of its safe position by that single result which alone is satisfactory; viz., the outflow of urine throngh it from the bladder. On my second trial with this instrument, I succeeded in passing the stricture. Small as it is, it was tightly held, but slowly and most carefully pushing it onwards for a short distance, on removing the stylet, the urine issued by drops.

Its construction is as follows. The instrument resembles in form, length, and curve, the ordinary catheter, and is made of silver. For the last two inches, however, it is perfectly solid, the extremity being in fact a fine metal probe. Accordingly, this ean be construeted at the outset, or afterwards adapted to any form or size required by any given case. However small it may be necessary to use the instrument, so small can this probe-pointed extremity be made. The hollow part or channel commences at about two and a half inches from the point, and a small eye is placed on the inner aspect of the curve. At this part the instrument gradually increases in diameter; first, to that of a No. 1, and then to nearly that of No. 2, which latter it continues throughout the whole shaft. The whole is strengthened by a small steel rod or stylet, which accurately fills the interior, and to which the handle is affixed. The small eye cannot therefore become blocked up with mucus or other matters. Moreover, the rod screws in, and gives to the instrument the most perfect solidity. A simple arrangement, which can be understood better by ex arnining the instrument than by any verbal description, permits the handle to slide, and be affixed to any part of the shaft, and enables the operator to use it either as a short or a long probe: the former condition being extremely convenient when a stricture is situated near to the external meatus of the urethra.

Wher the stricture has been passed, considerable care is necessary in guiding onwards the point through the canal behind, tó prevent its becoming engaged in the enlarged la. cunæ which are commonly found in the dilated urethra behind an old stricture.

This being safely accomplished, and the stylet removed, the urine will issue, by drops only, on account of the small size of

* Fig. 1. The right hand figure shews the instrument complete. The asterisk placed just below its eye, denotes the point at which the instrument becomes solid; continuing so to its extremity. The left hand figure is the steel stylet, unscrewed and removed from the instrument. 
the eye, but nevertheless in a manner which will soon relieve the patient, and which at once assures the surgeon of his complete success. The slight but very gradual increase in diameter which the lower end of the instrument exhibits, suffices also to dilate the stricture somewhat; and a No.1 catheter may generally be made to follow, on the withdrawal of the first instrument, a short time after its introduction. If doubt as to the practicability of this be entertained, a fine gum elastic tube may be passed into the bladder by first removing the handle and stylet, and screwing in its place a long steel rod, over which the tube may glide. No doubt that the safest and most satisfactory practice is to permit a small catheter to remain in the urethra a few hours until it can be replaced by a larger, and for this purpose it is convenient to employ a small bent tube, containing a stopcock, and adapted to the catheter, so that the patient can easily command the outflow of his urine, and at all events be secured from the unpleasant results which sometimes occur, when, a mere plus of wood being placed in its orifice, the urine dribbles backwards along the shaft of the catheter upon the patient's person. An entire set of catheters may be supplied with a single tube which fits every one of them as in a set, which I have long employed for the purpose, and which may be seen here.

$$
\text { [To be continued.] }
$$

Wimpole Street, Cavendish Square, 1857.

\section{CASES OF STRANGULATED HERNIA.}

By Draper Mackinder, M.D., F.R.C.S.Edin., etc., Gainsborough.

Fortunately for suffering humanity, the introduction of chloroform has rendered the surgeon's knife not only less formidable, but less frequently necessary ; and, perhaps, there is no class of our patients more deeply indebted to the friendly anæsthetic than the poor victims of hernia.

A rupture is an accident of frequent occurrence in this neighbourhood, often attributable, I think, in working people to the foolish custom of wearing tight inelastic belts and stays.

Several cases of strangulation have been under my care during the last few years, but I have only had occasion to operate in five, four of which recovered.

A short account of these, from the notes in my day-book, will not perhaps be unacceptable.

CASE I. The first case was that of a labouring man, aged 65 who had had a right inguinal hernia for twenty years. It had always been reducible, and had been supported by a truss until a few weeks previously, when he had been induced to leave the instrument off. After a hard day's work at the end of June, the gut came down, and was soon followed by the usual symptoms of pain, vomiting, etc. Strangulation had existed for twentyfour hours when I first saw him.

In consequence of the great tenderness over the hernial protrusion and the severity of the constitutional symptoms, after a short trial of the taxis under chloroform, I proceeded to operate by the old plan of opening the sac, which I found adherent. The man was kept well under the influence of opium for three days, and left his bed well in a fortnight.

Case II. The second case was a laundress, aged 45, a delicate woman of a spare habit of body, who had had a right femoral hernia for a long time, but had never attended to it. After lifting a heavy tub, she felt something give way, and was afterwards seized with pain, chilliness, and vomiting. I was not sent for until the strangulation had existed four days, when there were fæcal vomiting, great tympanitis, and jactitation. Reduction had been tried by a medical friend; and a short application of the taxis, with anrsthesia, not affording relief, I immediately cut down, opened the sac, divided the stricture, and returned the chocolate-coloured intestine.

The poor woman was kept under the influence of opium and ammonia for some days, and, with the assistance of good support, eventually did well.

CASE IIr. The third was a case of left femoral bernia, oc. curring in a charwoman, aged 40 . This woman had not previously observed a swelling, but felt something give way after jumping out of bed in a state of alarm, and using some exertion to open a window. When seen, she was cold, vomiting, and suffering great pain in the abdomen, which was tympanitic. The vomited material being stercoraceous, attention was at once directed to the usual hernial apertures, and a small knuckle of intestine detected in the left femoral region.

After the common remedies had failed to effect reduction,
I proceeded to operate, and divided the stricture without opening the sac. The gut was easily returned, and the woman was quite well in ten days.

CASE IV. A woman, Mrs. W., aged 48, of moderate circumstances, but immoderate size, weighing twenty-two stones, is the next on my list. This unfortunate patient had had an immense irreducible hernia for fourteen years, from which she had occasionally suffered so much, that on my first visit, Nov. 2nd, 1855, she declared her suffering to be wholly independent of the rupture. She was accordingly treated for colic; but the next day she had stercoraceous vomiting, and an aggravation of all the other symptoms. Fearing she would die, I advised her to avail herself of the poor chance that remained, and sub. mit to an operation; to which she then consented, and was immediately put under chloroform. The tumour was about the size of a child's head. The incision through the integuments was some eight inches long, and through a stratum of adipose tissue at least four inches thick. The intestine was found encircled by numerous bands of lymph, which were broken up, the gut replaced in its natural position, and the wound united by sutures, immense pieces of strapping, and several yards of bandages; for so enormously large was the pendulous abdomen, that the poor woman could only turn over by giving the body a complete swing. The sutures were soon torn out and useless. On the following day Mrs. W. appeared calm and comfortable, and the bowels had operated many times. On the third day, she was sitting upon the commode when I entered the room, and expressed herself well. The pain had subsided; but there was still occasional vomiting of a little fæcal matter up to the tenth day after the operation, when she had a sudden rigor, followed by pain in the right hypochondriac region, collapse, and death.

A post mortem was not allowed.

From the vomiting which followed the operation, and never entirely ceased till her death, though the bowels were acted upon more than twenty times, despite the repeated administration of opiates, it is but natural to infer that a portion of gut had been unrelieved of its strangulation.

This was certainly the most formidable operation for hernia that I ever witnessed, and my hopes for her recovery were never very sanguine. Indeed, from the all but universally fatal result of operations for umbilical hernia, nothing but a strong sense of duty would induce any one to use the knife in such cases.

CASE v. In the evening of September 13th, 1856, I was requested by my assistant, Mr. Henry Towle, to visit a man who had got a strangulated inguinal hernia, which he could not reduce. The patient, Geo. Smith, aged 29, a fair complexioned, stout, healthy sailor, who had been on shore a few days, gave the following history of his case. He was a volunteer during the disturbance in New Zealand in 1845 ; and, in consequence of the breaking of a hook of the scaling ladder which he was ascending at the block house of Kororareka, Bay of Islands, he fell a distance of fourteen feet astride some pailings, and injured his perinæum. Next day he perceived a small lump in the groin, and his testicles were inflamed, for which he was ordered a suspensory bandage. The lump in the groin continued when in the upright position; but no notice was taken until four years and a half afterwards, when an American surgeon ordered him to wear a truss. This he left off the day before the accident, considering himself cured.

On the morning the strangulation occurred, he ran a race for a dinner, won and ate it; and an hour and a half afterwards he felt very ill, went to bed, and discovered a large lump in his right groin. He complained of much pain at the pit of the stomach, had slight vomiting, and a quisk feeble pulse. There was a very tense oblong tumour extending from the symphysis pubis to within a couple of inches of the anterior superior spinous process of the ilium : in other words, an ellipsis with a conjugate diameter of about six inches. The taxis, with the ordinary concomitants, having failed, I at once, before the anæsthesia had passed off, cut down on the tumour, opened the sac, divided the stricture, and returned eighteen inches of congested intestine. A strong opiate was administered, the incision united by first intention, and the patient, to my surprise, was downstairs on the morning of the third day, and went to church on the seventh.

On a further examination, I found a considerable bulging of the right lower half of the abdominal wall, probably depending on a rupture of some of the fibres of the transverse or oblique muscles. For this I got the man to make himself a strong, broad, woollen belt to embrace the lower half of the abdomen, having a pad affixed thereto of sufficient size and 